\title{
Kinetics of Enolisation of Acetophenone and p-Bromoacetophenone: Comparative Studies
}

\author{
Swati Malhotra1, Dipika Jaspal ${ }^{2}$ * \\ ${ }^{1}$ Department of Chemistry, SLP Science College Gwalior, Madhya Pradesh, India \\ 2 Department of Applied Science, Symbiosis Institute of Technology, Symbiosis International \\ University, Lavale, Pune, Maharashtra, India
}

Received: 23rd March 2013; Revised: 21st June 2013; Accepted: 30th June 2013

\begin{abstract}
Biomolecules (Amino Acids) have been used as catalysts for the study of kinetics involved in enolisation of acetophenone and p-bromoacetophenone, and comparative study has been carried out. The process of enolisation has been studied by halogenation reactions using iodine. The stoichiometery was determined in each case and the kinetic reactions have been carried out to study the effect of catalyst and temperature. The enolisation process has been investigated as a bimolecular reaction. The rate of enolisation was of the order p-Bromoacetophenone $>$ Acetophenone depending on the type of substituent. The process studies follow Arrhenius equation. Values for various thermodynamic parameters like entropy $\left(\Delta \mathrm{S}^{\neq}\right)$and enthalpy $\left(\Delta \mathrm{H}^{\neq}\right)$ were found to be -2.126 e.u. \& -10.88 e.u. and $19.06 \mathrm{kcal}^{\mathrm{mol}}{ }^{-1} \& 19.01 \mathrm{kcal}^{-\mathrm{mol}}{ }^{-1}$ for acetophenone and pbromoacetophenone, respectively. (C) 2013 BCREC UNDIP. All rights reserved
\end{abstract}

Keywords: Amino Acids; Acetophenone; Enolisation; p-Bromoacetophenone; Catalysis

How to Cite: Malhotra, S., Jaspal, D. (2013). Kinetics of Enolisation of Acetophenone and pBromoacetophenone: Comparative Studies. Bulletin of Chemical Reaction Engineering \& Catalysis, 8(2): 105-109. (doi:10.9767/bcrec.8.2.4653.105-109)

Permalink/DOI: http://dx.doi.org/10.9767/bcrec.8.2.4653.105-109

\section{Introduction}

The phenomenon of enolisation is of utmost significance in the chemistry of aldehydes and ketones. The rate of enolisation is significantly affected by various factors like temperature, concentration and presence of catalyst. There has been no substantial study made on the enolisation reactions of acetophenone and p-bromoacetophenone till date as per the literature survey. Therefore this being the motivation, kinetics of enolisation reactions has been investigated for acetophenone and $p$ -

* Corresponding Author.

E-mail: sheriedipika_k@yahoo.co.in (J. Dipika),

Tel: +91-020-39116454, Fax: +91-020-39116260 bromoacetophenone under various conditions like temperature, concentration in the presence of catalysts.

Enolisation reactions can be studied by deuteration, recemization and halogenations [1-5]. Halogenation reaction, primarily iodination has been considered for the study of enolisation kinetics in the present research.

Kinetics of the process has been studied for the effect of the use of amino acids as catalyst. Amino acids and biomolecules viz. glycine and B-alinine which were obtained by the degradation of the proteins were tested as catalysts in the study of enolisation [6]. Glycine and B-alinine catalyzing the enolisation reaction contain two reactive groups, amino and a carboxyl group. These amino acids exists in 
the form of an internal salt known as Zwitter ion which is a dipolar ion.

The rate of the reaction has been studied and different thermodynamic parameters have been calculated. The present research will be helpful in understanding the chemistry behind the enolisation process and studying to what extent the different factors affect the rate of enolisation [7-15].

\section{Materials and Methods}

Kinetic runs were carried out in a thermostat (England Make) of 10 liter capacity fitted with an automated stirrer. Corning burette of grade ' $\mathrm{A}$ ' was used for performing the titrations. Throughout the investigations glassware of borosil was used. Acetophenone was procured from B.D.H England and p-Bromoacetophenone from Kochlight laboratories Ltd. Calnbrook bucks, England and both were of A.R. grade.

Stock solutions of $0.1 \mathrm{M}$ concentration were prepared by dissolving weighed amount of the ketones in $100 \%$ acetic acid, as these were insoluble in alcohol. $1 \mathrm{M}$ stock solution each of different amino acids was made in bidistilled water and was used within two days, after which fresh solutions were again made.

\subsection{Kinetic Measurement of Enolisation}

Long neck stoppered flasks were taken one of these containing $0.1 \mathrm{M}$ ketone and the other with the reactants i.e. acetic acid, water and iodine. The flasks were termostated at the desired temperature for about $30 \mathrm{~min} .5 \mathrm{ml}$ of the ketone was added to the flask containing the reactants and shaken thoroughly. An aliquot was immediately withdrawn and quenched in ice cold water in a 100 $\mathrm{ml}$ conical flask after which the amount of iodine was estimated by titration with $3 \times 10^{-3} \mathrm{M}$ Hypo solution using starch as an indicator. This indicated the concentration of iodine at zero time. The process was continued by withdrawing $5 \mathrm{~mL}$ aliquots at regular time intervals and determining the iodine used.

The rate constant in the above case can be represented as:

$$
k_{1}=\frac{2.303}{t} \log \frac{a}{a-x}
$$

Here, $\mathrm{k}_{1}$ the specific reaction rate, $\mathrm{a}$, is the initial concentration of iodine at zero time and $\mathrm{x}$ is the amount of iodine consumed in time $t$.

\subsection{Variation of Amino Acids}

A variation in the concentration of the amino acids was made in the range of $10.0 \times 10^{2}$ to $22.0 \times 10^{2} \mathrm{M}$ and the concentration of the other reagents were kept constant. Studies were carried out at intervals of $30 \mathrm{~min}$. This variation was done in the usual way taking the stock solutions and the rate constants were noted.

\subsection{Effect of temperature}

The effect of temperature differs in case of unimolecular (high activation energy) and bimolecular reactions (Low activation energy). In order to test the applicability of Arrhenius equation (Eqn. 2) iodometeric measurements were carried out at different temperatures ranging from $318 \mathrm{~K}$ to $333 \mathrm{~K}$ maintaining the concentration of the substrate and the amino acids constant.

$$
k_{1}=A \exp ^{(-E a / R T)}
$$

The rate constant $\left(\mathrm{k}_{1}\right)$ was first calculated and was plotted against the reciprocal of the absolute temperature (Figure 1). The slopes and intercepts of this graph provided the Arrhenius parameters. Various other thermodynamic parameters such as energy of activation (Ea), entropy of activation $\left(\Delta \mathrm{S}^{\neq}\right)$, frequency factor log PZ (A), enthalpy of activation $\left(\Delta H^{\neq}\right)$and free energy $\left(\Delta F^{\neq}\right)$were calculated using the below mentioned mathematical expressions:

$$
\begin{aligned}
& E a=2.303 \times \text { slope } \times 1.99 \times 10^{-5} \\
& \log P Z=\log A=\text { in tercept } T^{-1}
\end{aligned}
$$

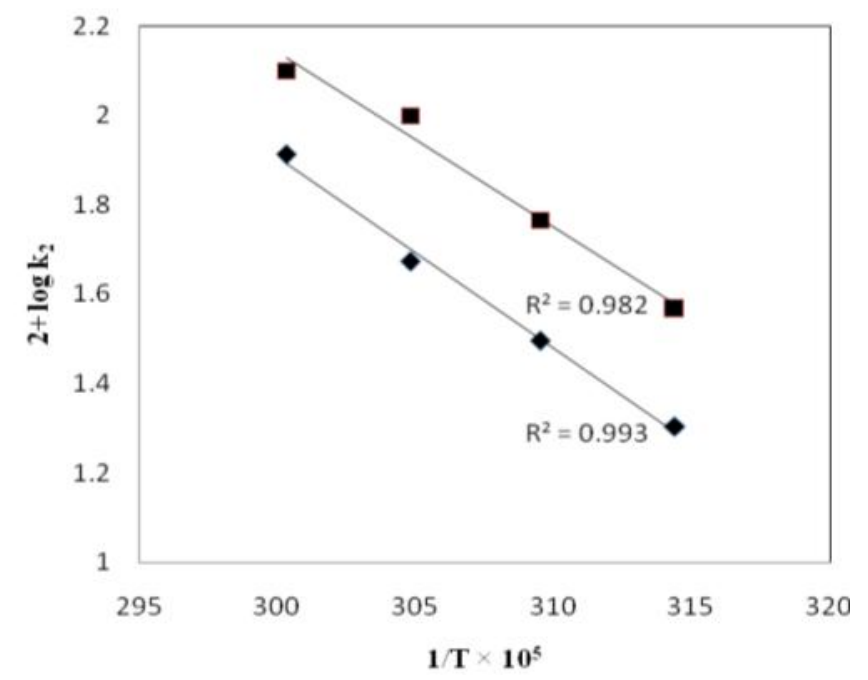

Figure 1. Arrhenius plots for Acetophenone and pBromo acetophenone 


$$
\begin{gathered}
P Z=\frac{K T}{h \cdot} e^{\frac{\Delta S^{\#}}{R}} \\
A=10^{13} \cdot e^{\frac{\Delta S^{\#}}{R}} \\
\Delta F^{\#}=\Delta H^{\#}-T \Delta S^{\#}
\end{gathered}
$$

In the above expressions $\mathrm{K}$ is the Boltzmann constant, $\mathrm{h}$ is the Plank's constant, $\mathrm{T}$ is the absolute temperature and $\mathrm{R}$ is the universal gas constant.

Equation (6) clearly indicates that positive or negative value of $\Delta \mathrm{S}^{\#}$ will depend upon whether $\mathrm{A}$ is greater or smaller than $10^{13}$. A positive value of $\Delta \mathrm{S}^{\#}$ i.e. $\mathrm{A}>10^{13}$ will corresponds to a more probable complex formation and the reaction is faster than the normal one.

The specific rate constants were calculated as per the equation given below:

$$
k_{2}=\frac{k_{1}}{[\text { ketone }] \times 60}
$$

\section{Results and Discussion}

\subsection{Variation of Catalyst}

Amino acids like 6 -alanin and glycine were tested as catalysts in the enolisation process for the two ketones as these are expected to show different catalytic activity. Amino acids form two equillibria involving three kind of species. At about $\mathrm{pH}$ 6.0, dipolar ion (Zwitter ion) species exists, which is converted to more protonated acid form with positive charge on nitrogen. At lower $\mathrm{pH}$ range however it is converted into more anionic species with a negative charge on oxygen. Since the rates of enolisation of the ketones are proportional to the concentration of amino acids hence the rates of enolisation are expected to be governed by the concentration of Zwitter ion species.

The velocity constants in this case to were found to increase with the increase in the concentration of the amino acids (Table 1). As in the above case p-bromoacetophenone again shows higher rate constant values $[16,17]$. The two amino acids show different catalytic effects by virtue of their different dipole moments (B-alanine 19.4D > glycine 11.6-15.7 D). The greater the dipole moment of the amino acid more is the separation of charge in the molecule and greater is the rate of enolisation. The obtained value in Table 2 were well in agreement however among the two amino acids the order of rate constants for B-alanin were of the order p- Bromoacetophenone $>$ Acetophenone whereas for glycine Acetophenone $>$ pBromoacetophenone.

\subsection{Variation of Temperature}

Plots of $\log \mathrm{k}_{2}$ versus $1 / \mathrm{T}$ give straight lines $\left(\mathrm{R}^{2}=\right.$ 0.993 and 0.982 for Acetophenone and pBromoacetophenone, respetively) confirming the applicability of Arrhenius equation [16, 17]. The slopes of these graphs were utilized for the calculation of Arrhenius parameters (Table 2 and 3). The data obtained from these studies have been potrayed in Tables 2 and 3. The magnitude of the parameters obtained, are indicative of the bimolecular nature of the enolisation reactions.

The rates are found in the order pBromoacetophenone $>$ acetophenone, thereby confirming that the presence of electron attracting groups facilitates the formation of enol thereby enhancing the rate. The findings are in accordance with the studies made by Hammett [18], according to whom the rate of any of the substituted compounds is related to the value for the unsubstituted compounds in terms of two parameters $\sigma$ and $\rho$. In

\begin{tabular}{|c|c|c|c|c|c|}
\hline \multirow{3}{*}{ Exp. No. } & \multirow{3}{*}{$\underset{\left(\mathrm{M} \times 10^{2}\right)}{\operatorname{Amino} \text { Acid }}$} & \multicolumn{4}{|c|}{$4+\log k_{1}$} \\
\hline & & \multicolumn{2}{|c|}{ Acetophenone } & \multicolumn{2}{|c|}{ p-Bromoacetophenone } \\
\hline & & $\beta$-alanin & glycine & $\beta$-alanin & glycine \\
\hline 1 & 10.0 & 3.5211 & 3.3978 & 3.7040 & 3.400 \\
\hline 2 & 14.0 & 3.6504 & 3.5146 & 3.7315 & 3.421 \\
\hline 3 & 18.0 & 3.7702 & 3.5914 & 3.854 & 3.4757 \\
\hline 4 & 20.0 & 3.8414 & 3.6162 & 3.889 & 3.4910 \\
\hline 5 & 22.0 & 3.8652 & 3.6468 & 3.930 & 3.5310 \\
\hline
\end{tabular}
the case of the rate constant the relationship is:

Table 1. Comparison of the rates of enolisation in the two ketones (Temp: $50{ }^{\circ} \mathrm{C}$ ) $[$ Ketone $]=0.1 \mathrm{M}$, $[$ Iodine $]=0.006 \mathrm{M},[\mathrm{AcOH}]=20 \%(\mathrm{v} / \mathrm{v})$ 
Table 2. Thermodynamic Parameters (Temp. $318 \mathrm{~K})$ [Ketone] $=0.1 \mathrm{M}$, [Iodine] $=0.006 \mathrm{M}$, [ B-alanin] $=$ $0.1 \mathrm{M}, \mathrm{AcOH}=20 \%(\mathrm{v} / \mathrm{v})$

\begin{tabular}{|c|c|c|c|c|c|}
\hline Ketone & $\begin{array}{c}\Delta \mathrm{Ea} \\
\left(\mathrm{kcal} \mathrm{mol}^{-1}\right)\end{array}$ & $\begin{array}{c}\mathrm{Pz} \\
\left(1 \mathrm{~mol}^{-1} \mathrm{~min}^{-1}\right)\end{array}$ & $\begin{array}{c}\Delta \mathbf{S}^{\neq} \\
\text {(e.u.) }\end{array}$ & $\begin{array}{c}\Delta \mathrm{H}^{\ddagger} \\
\text { (K. cal mol-1) }\end{array}$ & $\begin{array}{c}\Delta \mathrm{F}^{\neq} \\
(\text {K. cal mol-1) }\end{array}$ \\
\hline Acetophenone & 19.05 & $2.42 \times 10^{12}$ & -2.126 & 19.06 & 22.98 \\
\hline p-Bromoacetophenone & 19.06 & $4.4 \times 10^{14}$ & -10.88 & 19.01 & 22.53 \\
\hline
\end{tabular}

Table 3. Effect of Temperature $(\mathrm{K})$. $[$ Ketone $]=0.1 \mathrm{M}$, [Iodine $]=0.006 \mathrm{M},[B$-alanine $]=0.1 \mathrm{M},[\mathrm{AcOH}]=20 \%$

\begin{tabular}{|c|c|c|c|c|}
\hline Temperature (K) & 318 & 323 & 328 & 333 \\
\hline \multicolumn{5}{|l|}{ Acetophenone } \\
\hline $1 / \mathrm{T} \times 10^{5}$ & 314.4 & 309.5 & 304.8 & 300.3 \\
\hline $\begin{array}{l}\mathrm{k}_{2}\left(\mathrm{k}_{1} / \mathrm{subs} . \text { conc. }\right) \\
\text { l. } \mathrm{mol}^{-1} \mathrm{~min}^{-1}\end{array}$ & 0.20 & 0.31 & 0.47 & 0.81 \\
\hline $2+\log \mathrm{k}_{2}$ & 1.30 & 1.49 & 1.67 & 1.91 \\
\hline $5+\log \mathrm{k}_{2} / \mathrm{T}$ & 1.79 & 1.98 & 2.12 & 2.38 \\
\hline \multicolumn{5}{|l|}{ p-Bromoactophenone } \\
\hline $1 / \mathrm{T} \times 10^{5}$ & 314.4 & 309.5 & 304.8 & 300.3 \\
\hline $\begin{array}{l}\mathrm{k}_{2}\left(\mathrm{k}_{1} / \mathrm{subs} \text {. conc.) }\right. \\
\text { l. } \mathrm{mol}^{-1} \mathrm{~min}^{-1}\end{array}$ & 0.36 & 0.58 & 0.95 & 1.14 \\
\hline $2+\log \mathrm{k}_{2}$ & 1.56 & 1.76 & 1.99 & 2.10 \\
\hline $5+\log \mathrm{k}_{2} / \mathrm{T}$ & 2.05 & 2.25 & 2.46 & 2.52 \\
\hline
\end{tabular}

$$
\log k=\log k_{0}+\varnothing P
$$

where, $\mathrm{k}_{0}$ is the rate constant of the parent compound. The parameter $\sigma$ depends only on the substituent whereas $\rho$ is the reaction constant. Substituent with positive $\sigma$ values, are strong electron attractors and with negative values are weak electron attractors. Reactions with positive $\rho$ values take place at a faster rate due to electron withdrawal from the benzene ring, whereas those with negative values are retarded by electron withdrawal.

The results of the rates obtained in the present experimentation with positive and negative substituents constant $\left(\mathrm{CH}_{3}(-0.07) \& \mathrm{Br}(0.39)\right)$ were in accordance with Hemmett. This further confirms that the electron attracting groups increase the rate whereas the electron repelling groups show an adverse affect on the rate.

The mechanism has been explained by chemical Equations (9) \& (10) as follow:

$$
>\mathrm{CH}-\left.\right|_{\mathrm{x}} ^{+}+\underset{\substack{\text { acid } \\ \text { eadyed }}}{\longrightarrow}>\mathrm{CH}-\underset{\mathrm{C}}{\mathrm{C}}=\mathrm{O}
$$

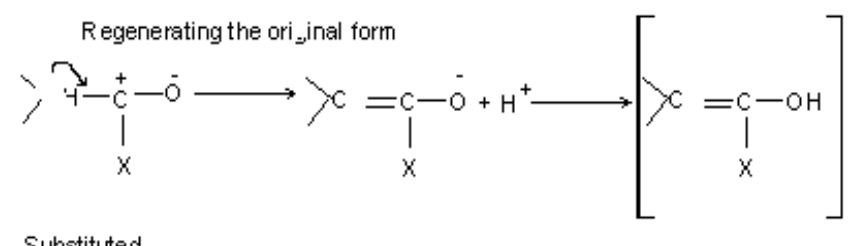

Substituted

acetophenone keto fom

enol fom

A significant work was done by Watson et al. [19] has suggested that in a proper collision, at appropriate temperature with acid catalyst, energy is communicated to the groups and semipolar form becomes the main participant in the resonance state. This is then followed by an immediate transformation either regenerating the original form as per Equation (9) or leading to the production of the enol form according to Equation (10). 
At this point the rate of the prototropic change depends upon the speeds of reaction of ketone and the catalyst and also the proportion of the energised form present which undergoes transformation as shown in Equation (10).

\section{Conclusions}

It is concluded that the rate of enolisation in case of both the ketones is dependent upon the concentration of amino acids and temperature. Substituted acetophenone, i.e. p-bromoaceto-phenone, shows greater reaction velocities in comparison to acetophenone due to the presence of electron withdrawing bromo group. The enolisation is found to be bimolecular reaction in nature. The B-alanin shows greater reaction rates in comparison to glycine for both the ketones.

\section{Acknowledgments}

One of the authors (SM) is thankful to CSIR for the fellowship provided for the research.

\section{References}

[1] Fontana, A., and More O'Ferrall, R.A. (1994). Equilibrium Constants for Ionisation and Enolisation of 2-Phenylacetylfuran. J. Chem. Soc. Perkin Trans,. 212: 2453-2459.

[2] Khirwar, S.S. (2010). Kinetics of the Enolisation of pEthoxyAcetophenone Catalysed by Amino Acids. Oriental J. Chem. 26: 1037-1042.

[3] Maria, P. D., Fontana, A., Siani, G., Spinelli, D. (1998). Kinetics of the Enolisation Reactions of 3acetyl-2,5-dimethylfuran and of 2-Acetylselenophene. Eur. J. Org. Chem. 9: 1867-1872.

[4] Ahmed, M.K.S., Bharatam, P.V. (2005). Importance of sulfoxidation in rapid racemisation of glitazones. Indian J. Chem. 44: 600-606.

[5] Ariza, X., Asins, G., Garcia, J., Hegardt, F.G., Makowski, K., Serra, D., Velasco, J. (2010). Preparation of a-labeled aldehydes by base-catalyzed exchange reactions. J. Labell. J. Comp. Radioharm. 53: 556-558.

[6] Craig, W. M., Broderick, G. A. (1984). Amino Acids Released During Protein Degradation By Rumen Microbes. J. Anim. Sci. 58: 436-443.

[7] Dobhal, B., Farooqui, M., Ubale, M. (2010). Kinetics of Permagnetic oxidation of 4-hydroxy Benzaldehyde in acidic media. Int. J. Chem. Tech. Res. 2: 443-446.
[8] Singh, B., Pandey, L., Sharma, J., Pandey, S.M. (1982). Mechanism of oxidation of some aliphatic ketones by $\mathrm{N}$-bromosuccinimide in acidic media. Tetrahedron 38: 169-172.

[9] Tandon, P.K., Kumar, S., Srivastava, M., Khanam, S. Z., Singh, S. B. (2007). Oxidation of hydrates of cyclic ketones by alkaline hexacyanoferrate(III). J. Mol. Cat. A: Chem. 261: 282-287.

[10] Tandon, P. K., Sehgal, S., Singh, A. K., Kumar, S.M. (2006). Oxidation of cyclic ketones by cerium(IV) in presence of iridium(III) chloride. $J$. Mol. Cat A: Chem. 258: 320-326.

[11] Raillard, C., Hequet, V., Cloirec, P., Le Legrand, J. (2004). Kinetic study of ketones photocatalyic oxidation I gas phase using $\mathrm{TiO}_{2}$ containing paper: effect of water vapor. J. Photochem. Photobiol. A: Chem. 163: 425-431.

[12] Zacuto, M. J., Cai, D. (2005). Iodine-mediated Zselective oxidation of ketones to a,b-unsaturated esters: synthesis and mechanistic studies. Tetrahedron Letters 46: 8289-8292.

[13] Mahadevappa, D.S., Mohan, K., Ananda, S. (1986). Electrolytic partial fluorination of organic compounds. Part 48: Anodic fluorination of 2cyano-1-methylpyrrole. Tetrahedron 42: 4857 4860 .

[14] Escobar, G.P., Beroy, A.Q., Pina Iritia, M.P., Huerta, H. (2004). Kinetic study of the combustion of methyl-ethyl ketone over a-hematite catalyst. Chem. Eng. J. 102: 107-117.

[15] Agarwal, A., Sharma, G., Khandelwal, C.L., Sharma, P.D. (2002). Kinetics and Mechanism of Oxidation of Mannitol by Sulphato-cerium(IV) Species in Aqueous Acid Medium. Inorg. Reac. Mech. 4: 233-239.

[16] Malhotra, S., Jaspal, D. (2011). Study of Effect of Catalyst and Solvent on the Enolisation Process of p-Bromoacetophenone. Bull. Catal. Soc. India. 10: 1-6.

[17] Malhotra, S., Jaspal, D. (2012). Kinetics of Amino Acid Catalyzed Enolisation of Acetophenone. J. Chem. Pharm. Res. 4: 239-245.

[18] Hansch, C., Leo A., Taft, R. W. (1991). A survey of Hammett substituent constants and resonance and field parameters. Chem. Rev. 91: 165-195.

[19] Watson, H.B., Nathan, W.S., Laurie, L. L. (1935). The Acidities of Ketones and the Mechanism of Prototropic Change. J. Chem. Phys. 3: 170-174. 